\title{
Seasonal heat stress alters the milk yield, antioxidative levels and serum metabolites in primiparous and 3 multiparous dairy cows
}

\section{Xue Chen}

Jilin Agricultural University

Jia Nan Dong

Jilin Agricultural University

Ji Ye Rong

Jilin Agricultural University

Jun Xiao

Jilin Agricultural University

Wei Zhao

Jilin Agricultural University

Natnael D. Aschalew

Jilin Agricultural University

Xue Feng Zhang

Jilin Agricultural University

\section{Tao Wang}

Jilin Agricultural University

Guixin Qin

Jilin Agricultural University

Zhe Sun ( $\nabla$ sunzhe198615@163.com )

Jilin Agricultural University https://orcid.org/0000-0003-1872-2194

Yuguo Zhen

Jilin Agricultural University

\section{Research Article}

Keywords: Early lactation, Milk yield, Oxidative status, Serum metabolites, Heat stress

Posted Date: July 26th, 2021

DOI: https://doi.org/10.21203/rs.3.rs-696285/v1 
License: (c) (i) This work is licensed under a Creative Commons Attribution 4.0 International License. Read Full License 
Xue Chen ${ }^{1,6} \cdot$ Jia Nan Dong ${ }^{1}$ Ji Ye Rong ${ }^{1}$ Jun Xiao ${ }^{1,6}$. Wei Zhao ${ }^{1,6} \cdot$ Natnael D. Aschalew ${ }^{1}$. Xue Feng Changchun Borui Science \& Technology Co., Ltd, Changchun 130118, P.R. China

$11{ }^{4}$ Key Laboratory of Animal Production, Product Quality and Security, Ministry of Education, Jilin Agricultural University, Changchun 130118, P.R. China

\section{Abstract}

This study aimed to explore the seasonal heat stress affects the milk yield, antioxidative levels and serum metabolites in primiparous and multiparous dairy cows during early lactation. A total of two hundred dairy cows were selected according to their calving months (June, temperature humidity index (THI) $=66.72$; July, THI=70.30; August, THI=69.32; September, THI=67.20; October, THI=59.45). Blood samples were collected on day $0,21,50,80,100$ after calving for serum oxidative status analysis and milk yield was recorded every day. The lower average daily milk yield in cows that calved in June and July $(\mathrm{P}<0.05)$, and average daily milk yield of multiparous cows was higher than that of primiparous cows that calved in the same month $(\mathrm{P}<0.05)$, suggesting that seasonal (June) heat stress negatively affected milk yield in both primiparous and multiparous cows at early lactation. Besides, 15 and 11 serum metabolites were changed in heat stress (average $\mathrm{THI}=70.30)$ group compared with non heat stress (average $\mathrm{THI}=59.45)$ group in primiparous cows and multiparous cows, respectively. These metabolites were mainly involved in the pathways of aminoacyl-tRNA biosynthesis, glyoxylate and dicarboxylate metabolism, and the metabolism of glycine, serine and threonine. These data suggested that heat stress negatively affected the milk yield and thus caused the the elevation of 
29 the serum oxidative and antioxidative index Metabolic biomarkers associated with the heat stress in serum were found 30 which providing the basement of evaluating indicator between heat stress and non heat stress groups in primiparous and 31 multiparous cows.

32 Key words Early lactation, Milk yield, Oxidative status, Serum metabolites, Heat stress \# Corresponding author: Zhe Sun, sunzhe198615@163.com; Yu Guo Zhen, nickzhen@263.net.

\section{Declarations}

\section{Funding}

This study was supported by the Jilin Province Major Scientifific \& Technological Achievement Transformation Project (20160301003NY), Jilin Province Feed Engineering and Technology Research Center (20170623075TC) and the 2021 Scientific and Technological Developing Scheme of Jilin Province.

\section{Conflict of interest}

The Authors declare that they have no conflict of interest.

\section{Ethics approval}

The cows were managed according to the guidelines for the care and use of experimental animals of Jilin Agricultural University (JLAUACUC-2018-019).

\section{Consent to participate}

Not applicable.

\section{Consent for publication}

Not applicable.

\section{Data availability}

All the data are included in the manuscript.

\section{Code availability}


Not applicable.

52

53

54

55

56

\section{Authors' contributions}

ZS and YZ contributed to conception and design of the study. XC, ND, YR, XQ and FZ organized the database.

54 XC, ZS performed the statistical analysis. XC and SZ wrote the first draft of the manuscript. XC, TW, JX, WZ and ND

5 wrote sections of the manuscript. All authors contributed to manuscript revision, read, and approved the submitted 6 version. 


\section{Introduction}

The effects of heat stress on dairy cows are multifactorial and not only have great impact on the productivity of cows, present hazards to animal health and the oxidative-antioxidative balance, and even negatively affect an animal's offspring when they mature to adulthood (Dahl et al. 2017). It has been reported that THI is a major factor that can decrease the milk production of dairy cows when it is higher than 72 , and which usually considered the threshold of heat stress (Du et al. 1996(a); Du et al. 1996(b)). Milk yield is closely related to heat stress especially for the high-producing cows (Gantner et al. 2017). Ravagnolo et al. (2000) founded that milk yield declines by about $0.2 \mathrm{~kg}$ when THI (> 72) increased one unit. According to Kadzere et al. (2002) and Igono and Johnson (1990), cows in early lactation are more sensitive to heat stress than those in late lactation.THI has been used as an indicator of thermal comfort for dairy cows (Savaliya et al. 2019).

Many studies have assessed oxidative status by monitoring malondialdehyde (MDA) levels since increased MDA concentration is a biomarker of free radical-mediated damage and oxidative stress (Bouwstra, et al. 2008; Castillo et al. 2006) and antioxidant enzymes like superoxide dismutase (SOD) and glutathione peroxidase (GSH-PX) that represent major antioxidant responses by protecting the cells against increased reactive oxygen species (Konvicna et al. 2015). Metabolomics is a powerful analytical technology for understanding biological systems from hundreds of thousands of low-molecular weight metabolites in animals, and gas chromatography mass spectrometry (GC-MS) has also been used in metabolomics studies to provide a global understanding of the pathophysiological changes brought about by the environment (Zhao et al. 2015). For example, Tian et al. (2016) used metabolomics to study the heat stress candidate biomarkers in milk serum. We hypothesized that the damage degree via THI before and after calving and serum metabolites associated with the heat stress on primiparous and multiparous cows would be different. Therefore, this study investigated the effect of THI on the milk yield, oxidative status, and serum metabolites in primiparous and 
multiparous cows during early lactation. Our findings may provide guidance for the management of heat stress in dairy farms and draw people's more attention to the health of dairy cows.

\section{Materials and Methods}

\section{Animals and experimental design}

This study was performed from June to the following February (next year) at a commercial dairy farm in Shandong Province, P.R. China. Primiparous Holstein cows $(\mathrm{n}=100)$ and multiparous (parity: $2.5 \pm 0.5)$ Holstein cows $(\mathrm{n}=100)$ were selected according to their calving days in June, July, August, September and October, respectively. All the cows suffered different THI before and after calving. All experimental cows were fed the total mixed ration (TMR) ad libitum as described previously (Zhao et al. 2019). Air temperature and humidity at a height of $1.5 \mathrm{~m}$ above the ground at both ends and in the middle of the cowshed were recorded three times per day. Average daily temperature humidity index (THI) was calculated every day (NRC, 1971). The cows were managed according to the guidelines for the care and use of experimental animals of Jilin Agricultural University (JLAUACUC-2018-019).

\section{Sample's collection}

Blood was individually sampled from coccygeal veins on the calving day and $3-4 \mathrm{~h}$ after the morning feed on $\mathrm{d} 0$, $21,50,80$, and 100. Serum was collected after centrifuging at $3000 \mathrm{rpm}$ at $4^{\circ} \mathrm{C}$ for $10 \mathrm{~min}$ and stored at $-40^{\circ} \mathrm{C}$ for the latter analysis.

\section{Oxidative and antioxidative index analysis}

MDA, SOD, GSH-PX, and total antioxidant capacity (T-AOC) in serum were analyzed using a commercial bovine enzyme-linked immunosorbent assay kit (Shanghai Enzyme-linked Biotechnology Co. Ltd., Shanghai, China).

\section{GC-MS analysis}

The serum of dairy cows with the highest THI (July-calved, average THI $=70.30)$ and lowest THI (October-calved, 
average THI $=59.45)$ were selected for GC-MS analysis (sampling on calving day from cows calved in July and October, respectively). Thus, the cows that calved in July and October were in the heat stress (HS) group and in non-heat stress (NHS) group, respectively. The serum samples $(100 \mu \mathrm{L})$ and methoxyamine hydrochloride $(20 \mu \mathrm{L}, 0.3$ $\mathrm{mg} / \mathrm{mL}$ ) were mixed with $300 \mu 1$ methyl alcohol:chloroform (3:1) for $30 \mathrm{~s}$. After approximately 10 min latter, the mixed liquor was centrifuged at $12,000 \times \mathrm{g}$ at $4^{\circ} \mathrm{C}$ for $10 \mathrm{~min}$. The supernatant $(300 \mu \mathrm{l})$ was transferred to a centrifugal tube and dried using nitrogen gas. Subsequently, a $60 \mu \mathrm{L}$ solution (methoxyamine hydrochloride and pyridine) was added to the serum samples and incubated in a water bath at $37^{\circ} \mathrm{C}$ for $120 \mathrm{~min}$. After that, $60 \mu \mathrm{l}$ BSTFA (bis(trimethylsilyl)-trifluoroacet-amide) with $1 \%$ TMCS (trimethylchlorosilane) was added and incubated at $37^{\circ} \mathrm{C}$ for $60 \mathrm{~min}$. The samples were centrifuged at $13,000 \times \mathrm{g}$ at $4^{\circ} \mathrm{C}$ for $5 \mathrm{~min}$, and then $50 \mu 1$ supernatant of each sample was transferred to a GC vial. Each sample $(1 \mu \mathrm{l})$ was injected into an Agilent 7890/5975C system equipped with a fused silica capillary column $(30.0 \mathrm{~m} \times 0.25 \mathrm{~mm}$ i.d.) with a $0.25-\mu \mathrm{m}$ HP-5MS stationary phase (Agilent, Shanghai, China) (Chen et al. 2019).

\section{Statistical analyses}

The THI, milk yield, serum oxidative and antioxidative index, and Pearson correlation were analyzed using SPSS computer software (SPSS Statistics for Windows, Version 17.0; Chicago: SPSS Inc.), and P-values < 0.05 were statistically considered to be significant. Metabolic data was preprocessed including noise reduction, retention time correction, peak alignment, and other data standardization using AMDIS in Agilent, and then analyzed by SIMCA 14.0 software (Umetrics AB, Umeå, Sweden). Principal component analysis (PCA) was performed on the data to visualize the sample distribution and separation trends. An orthogonal partial least squares-discriminate analysis (OPLS-DA) model was used to identify differences in metabolites. Both the variable importance in the projection (VIP $>1$ ) values and Student's t-test $(P<0.05)$ were compared to find potential metabolites. 
120

121

122

123

124

125

126

127

128

129

130

131

\section{Results}

\section{Variation of temperature humidity index (THI) during experimental period}

The maximum THI, minimum THI, and average THI by month during the experiment are shown in Fig. 1. Briefly, the average THI decreased from July to January. Average THI values in July and August were higher than that in other months $(P<0.05)$. During the calving time (from June to October), the THI in October was lower than in other months $(P<0.05)$. The maximum THI values in June, July, and August were $74.78,75.65$, and 75.17, respectively. All of these maximum THI values were higher than 72, which are in the range of heat stress for dairy cows (Armstrong 1994) and recent data indicates that a THI of approximately 68 affected the milk yield of high-yielding dairy cows (Zimbelman et al. 2009), consistently, we found that cows were affected by heat stress in June, July, and August months.

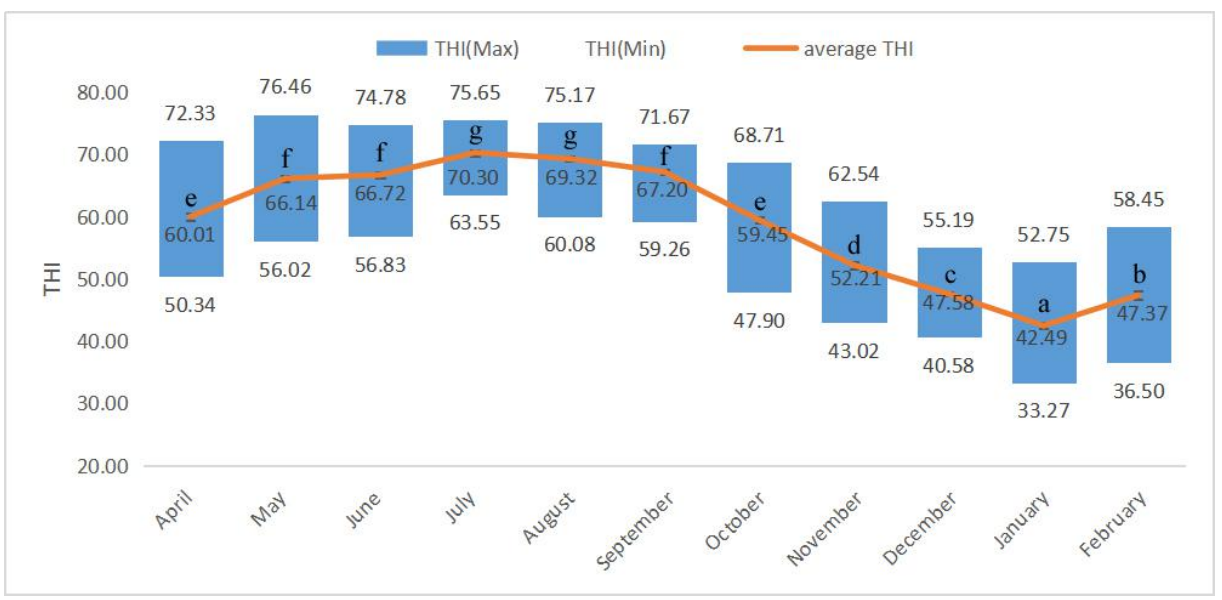

Fig. 1 Temperature humidity index (THI) during experimental period

a-f : A different letter means significant difference $(P<0.05)$ and same letter means no significant difference $(P>0.05)$ among different months

\section{Milk yield}

The effect of different calculated THI before and after calving on the cows as shown in Table 1. The cows that calved in June and July suffered high calculated THI after calving. The average daily milk yield (from 1- 100 days) and average daily milk yield after peak milk to 100 days of the primiparous cows that calved in June and July were lower 
136 than those calved in September and October $(P<0.05)$. No significant difference was found among multiparous cows

137 that calved in different months $(P>0.05)$. And average daily milk yield after peak milk to 100 days of multiparous

138 cows that calved in June were lower than those calved in the other months $(P<0.05)$. In the same calving month, the

139 average daily milk yield of multiparous cows over 100 days and average daily milk yield after peak milk to 100 days

140 were higher than that of primiparous cows $(P<0.05)$. When compared with the cows that calved in June, the average

141 daily milk yield of primiparous cows that calved in September and October increased by $19.15 \%$ and $13.83 \%$,

142 respectively. However, the average daily milk yield of multiparous cows increased by $2.86 \%$ and $7.64 \%$, respectively.

143 Milk yield negatively correlated with THI in both primiparous cows and multiparous cows $(P<0.05)$.

144 Table 1 Effect of temperature humidity indexes (THI) on milk yield ( $\mathrm{kg} / \mathrm{d})$

\begin{tabular}{|c|c|c|c|c|c|}
\hline Calving month & June & July & August & September & October \\
\hline Average THI (100 days) & $69.08 \pm 0.48^{\mathrm{e}}$ & $66.00 \pm 0.80^{\mathrm{d}}$ & $60.70 \pm 1.18^{c}$ & $53.04 \pm 1.07^{\mathrm{b}}$ & $49.16 \pm 1.04^{\mathrm{a}}$ \\
\hline Calculated & & & & & \\
\hline calving, $>72)$ & 1549.13 & 2361.60 & 2947.86 & 3240.90 & 3240.90 \\
\hline Calculated THI (after & 1691.77 & 879.29 & 293.03 & 0.00 & 0.00 \\
\hline calving, $>72$ ) & & & & & \\
\hline Average daily milk yield (ADMY, & & & $39.06 \pm 1.26^{\mathrm{Aa}}$ & & $40.83 \pm 0.76^{\mathrm{A}}$ \\
\hline & $35.87 \pm 1.26^{\mathrm{Aa}}$ & $35.67 \pm 1.93^{\mathrm{Aa}}$ & & $42.74 \pm 1.11^{\mathrm{Ab}}$ & \\
\hline 100 days, primiparous cows) & & & $\mathrm{b}$ & & $\mathrm{b}$ \\
\hline Average daily milk yield (ADMY, & & & & & \\
\hline & $47.63 \pm 1.26^{\mathrm{B}}$ & $46.69 \pm 1.54^{\mathrm{B}}$ & $48.88 \pm 2.04^{\mathrm{B}}$ & $48.99 \pm 0.76^{\mathrm{B}}$ & $51.27 \pm 2.07^{\mathrm{B}}$ \\
\hline 100 days, multiparous cows) & & & & & \\
\hline Average daily milk yield after & & & & & $44.04 \pm 1.24^{\mathrm{A}}$ \\
\hline & $37.22 \pm 0.88^{\mathrm{Aa}}$ & $38.20 \pm 0.81^{\mathrm{Ab}}$ & $42.26 \pm 1.31^{\mathrm{Ac}}$ & $44.55 \pm 1.18^{\mathrm{Ad}}$ & \\
\hline peak milk to 100 days & & & & & d \\
\hline
\end{tabular}


(primiparous cows)

Average daily milk yield after peak milk to 100 days(multiparous

$46.73 \pm 2.49^{\mathrm{Ba}}$

$49.66 \pm 2.31^{\mathrm{Bb}}$

$51.12 \pm 1.90^{\mathrm{Bc}}$

$51.51 \pm 1.48^{\mathrm{Bc}}$

$54.30 \pm 1.68^{\mathrm{B}}$

cows)

Correlation analysis of average

THI and ADMY (primiparous -0.65**

cows)

Correlation analysis of average

THI and ADMY(multiparous $-0.45^{* *}$

cows)

Calculated THI before calving: THI above 72 from April 1st to calving day were calculated.

Calculated THI after calving: THI above 72 during early lactation days (100 days) were calculated.

Different lowercase letters $(\mathrm{a}, \mathrm{b})$ means significant difference $(P<0.05)$ in the same row.

Different capital letters (A, B) means average daily milk yield and average daily milk yield after peak milk to 100 days is significantly different $(P<0.05)$ in the same column. 
156

157

158

160

161

162

163

164

165

166

167

other groups, and the peak milk yield and persistency of milk yield after peak milk to 100 days were lower than that of other groups. The downward trend of milk curve for multiparous cows was much more obvious than primiparous cows.

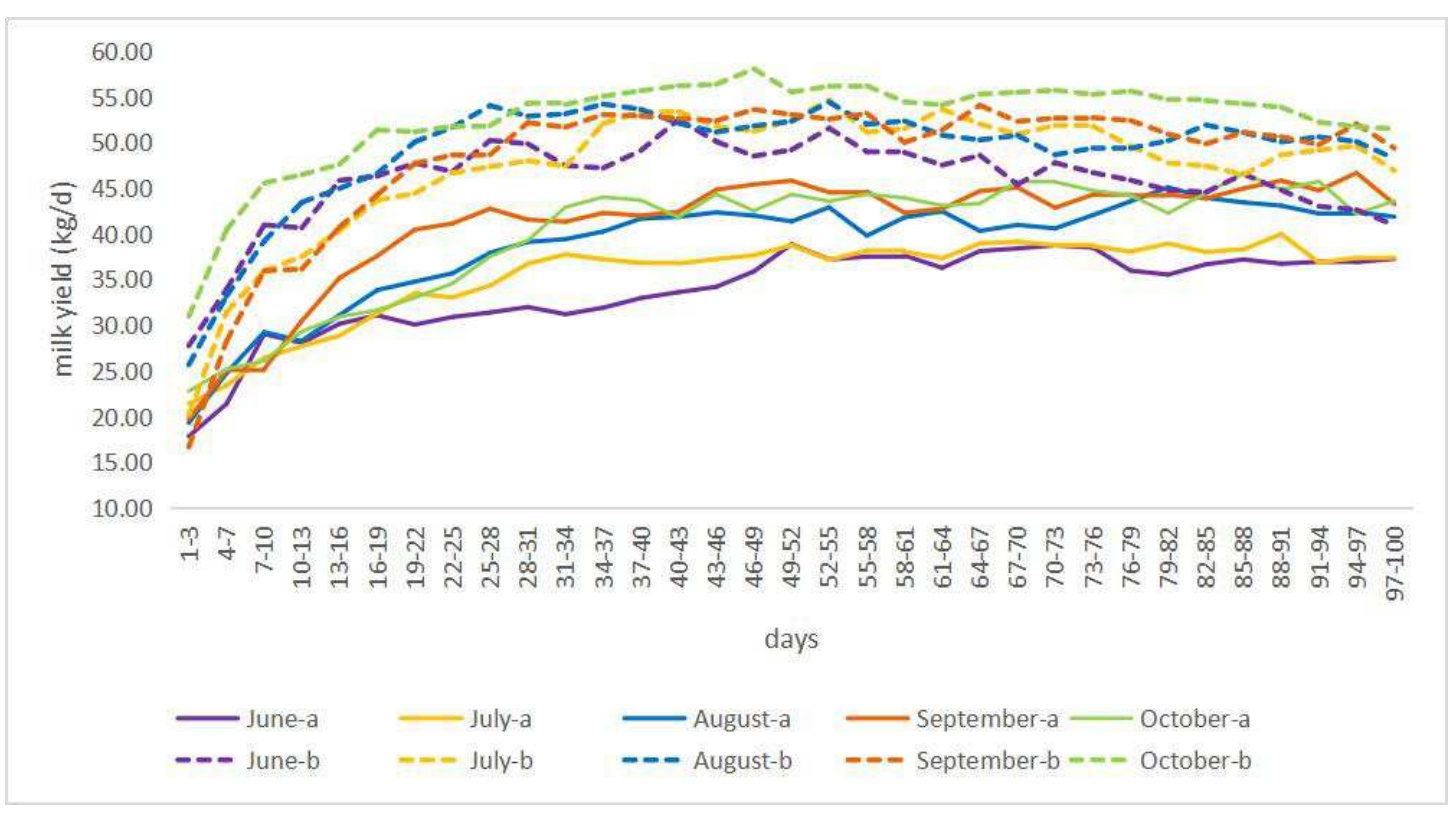

Fig. 2 Lactation curves of primiparous and multiparous cows from days1 to 100.

a: primiparous cows, b: multiparous cows.

\section{Oxidative and antioxidative index}

Our results showed that all of the serum oxidative indexes showed different variation trends during the early lactation period, however, the overall concentration of every index in primiparous cows was higher than that in multiparous cows in the same month (Fig. 3). On days 50 and 100, all the indexes were relatively low compared to other times. Although no significant difference in MDA, SOD, and T-AOC in serum was found among the groups in primiparous dairy cows on the calving day $(P>0.05)$, but GSH-Px of primiparous cows that calved in August, September, and October was significantly higher than that in June and July $(P<0.05)$. No significant differences were found in the above serum oxidative indexes were found in multiparous dairy cows on calving day. On day 21 after calving, SOD and GSH-PX values in cows that calved in September and October were significantly higher than in those that calved in June and July $(P<0.05)$. On day 50 after calving, SOD in primiparous cows that calved in October was 
171

172

173

174

175

176

177

178

179

180

highest and GSH-PX and T-AOC were lowest when compared with other groups $(P<0.05)$. GSH-PX in multiparous cows that calved in September and October was significantly higher than in those that calved in June and July $(P<$ 0.05). On 80 and 100 days after calving, MDA in primiparous cows that calved in June and July was significantly higher than that in cows that calved in October, and T-AOC in primiparous cows that calved in October was highest on day $80(P<0.05)$. SOD in multiparous cows that calved in September and October was significantly higher than that in those that calved in June on day $80(P<0.05)$. On day 100 after calving, GSH-PX in primiparous cows that calved in September and October was significantly higher than that in those that calved in June and July $(P<0.05)$. Positive Pearson correlation coefficients were observed among the serum oxidative indexes (MDA, SOD, GSH-PX and T-AOC) in primiparous cows and multiparous cows $(P<0.01)$ whereas no significant difference was found between THI and serum oxidative index (Fig. 4).

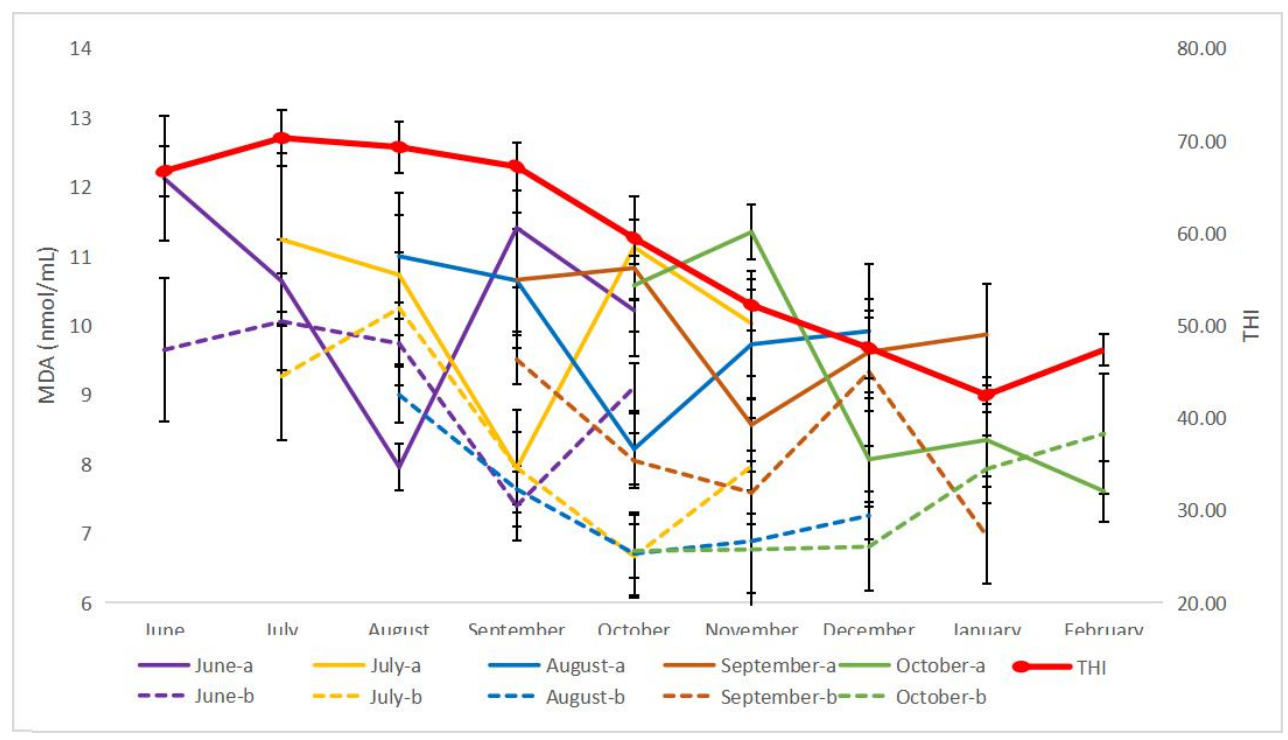



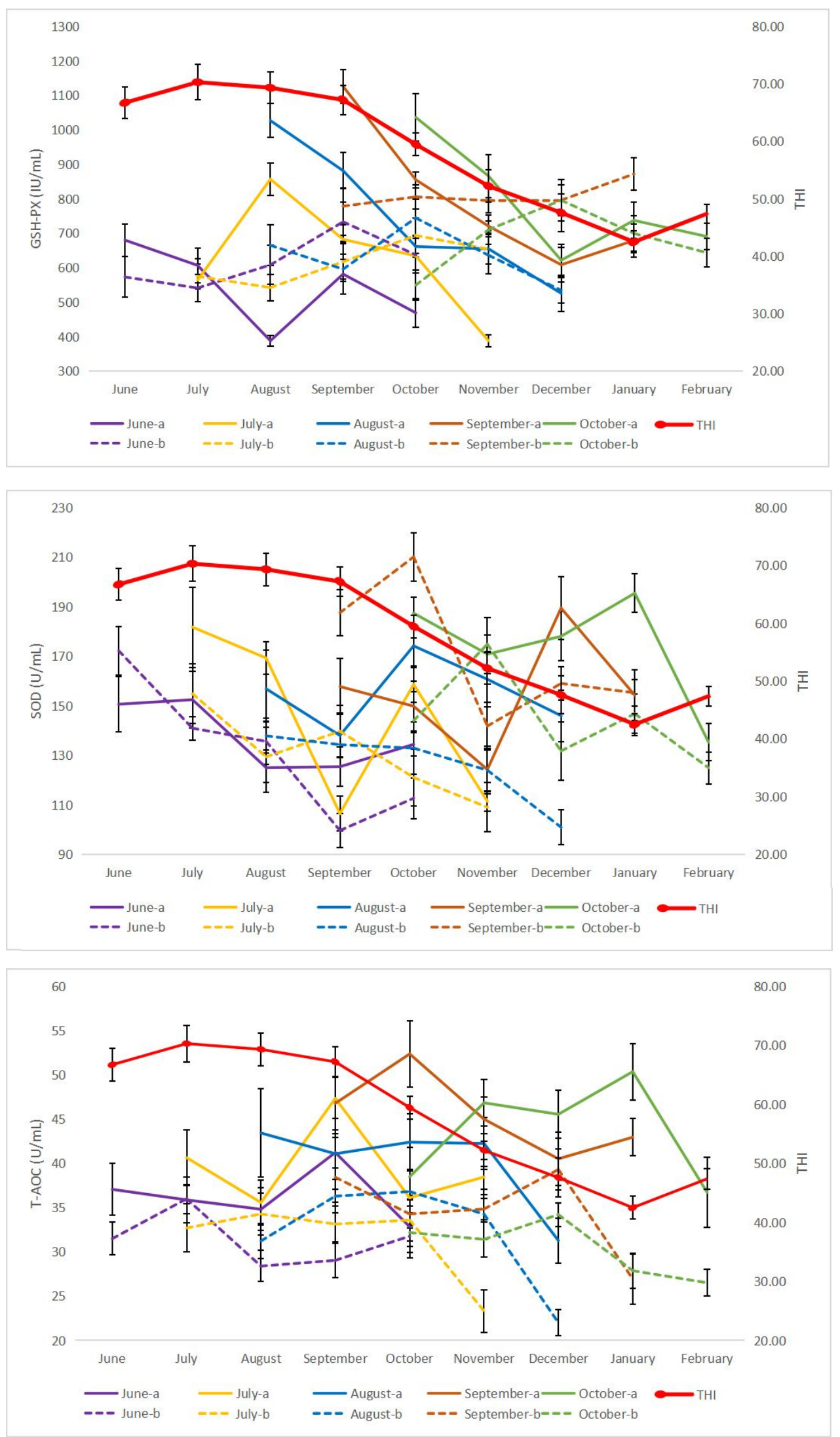

Fig. 3 Effect of temperature humidity indexes (THI) on serum oxidative indexes. 

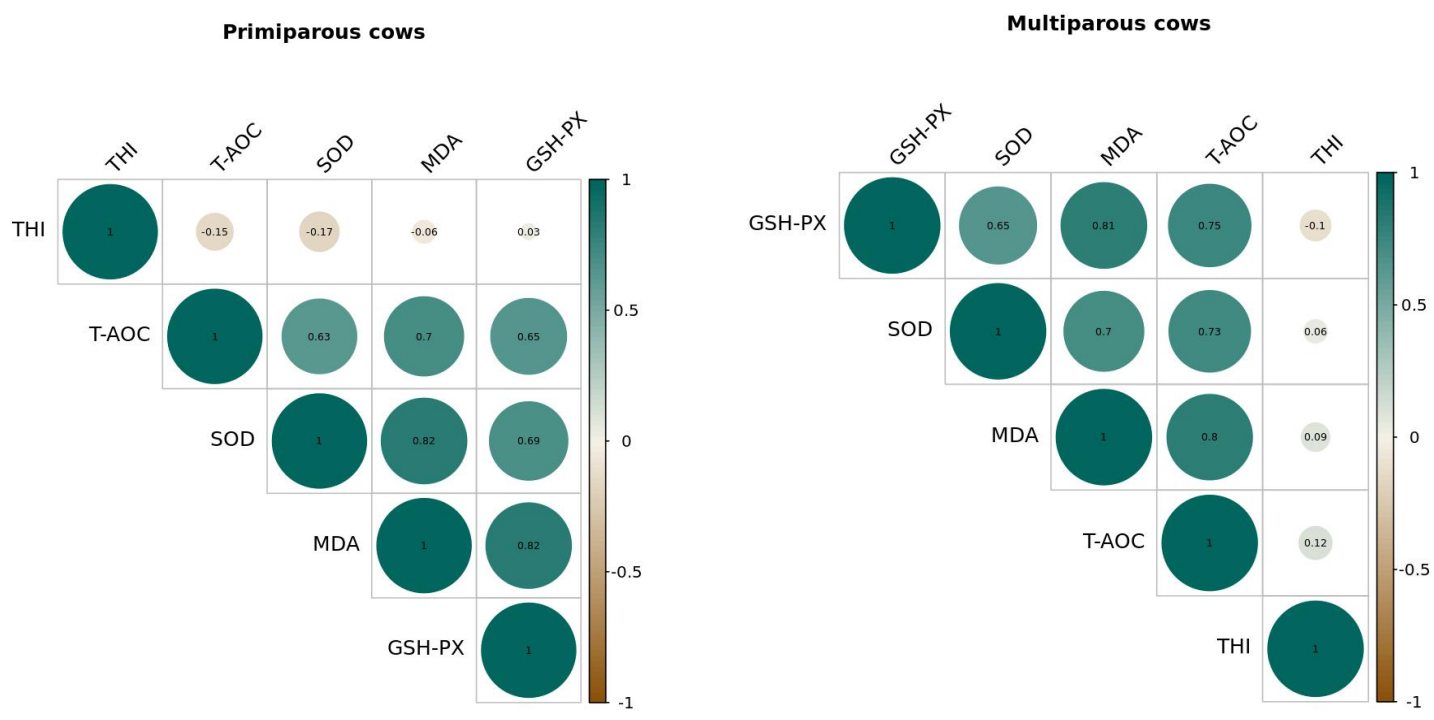

187

Fig. 4 Correlation among serum oxidative indexes and temperature humidity index (THI)

\section{Metabolic candidate and pathway analysis}

The original data obtained from GC/MS were classified into a two-dimensional matrix, and then analyzed by SIMCA-P+14.0 software for PCA pattern recognition. Serum PCA plots had an obvious separation among different groups, and all the samples were within the 95\% confidence interval (Fig. 5-A). On the basis of the PCA model, OPLS-DA was used to further analyze the different metabolites in serum between HS and NHS groups of primiparous cows and multiparous cows (Fig. 5-B, C).

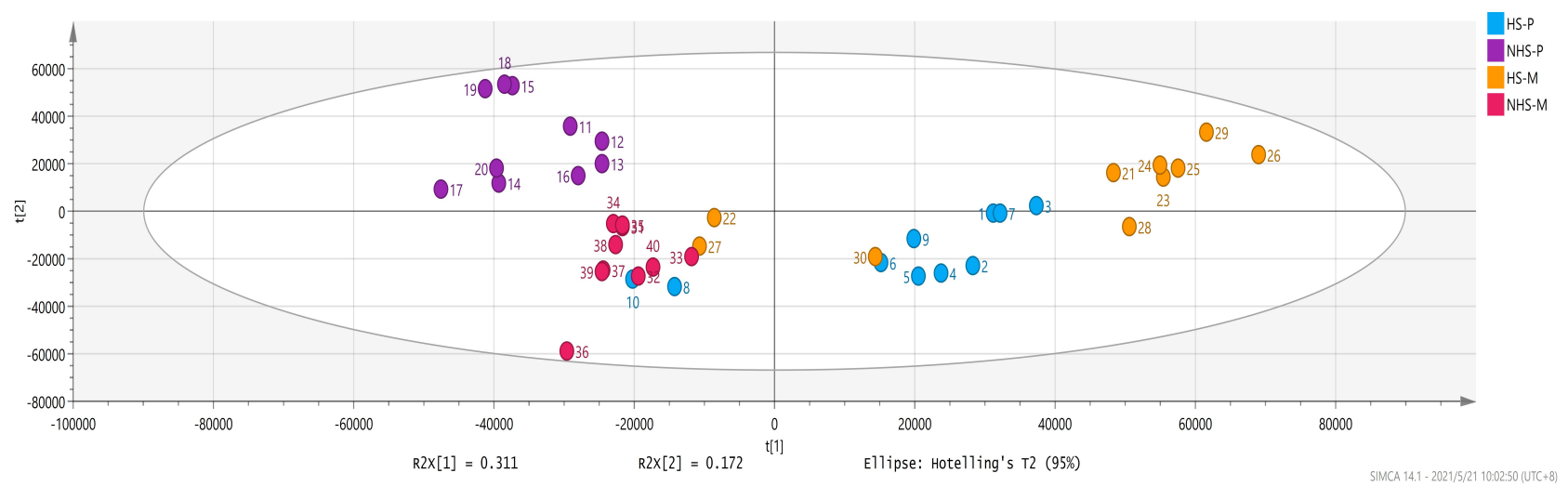

A 
197

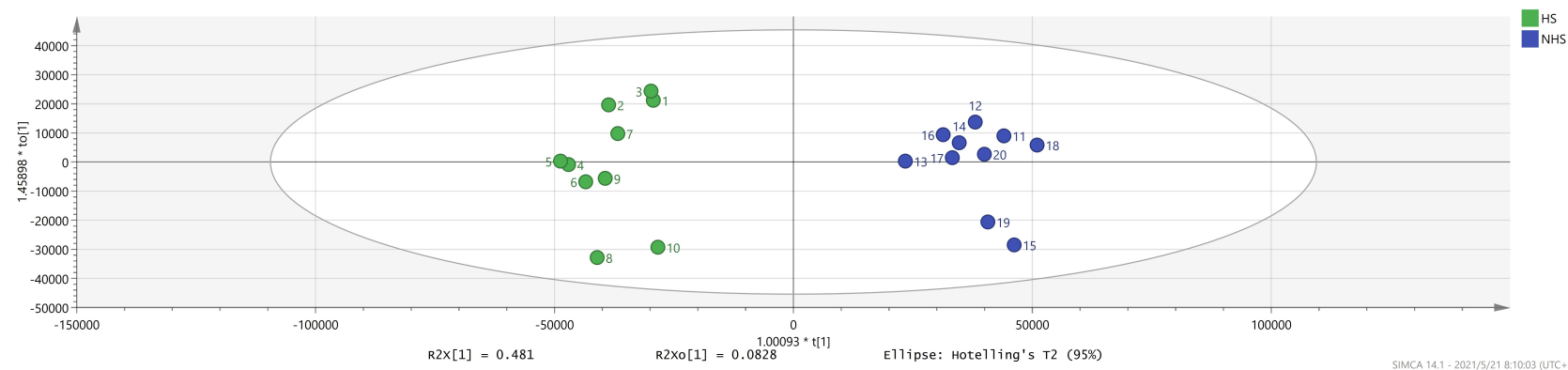

B

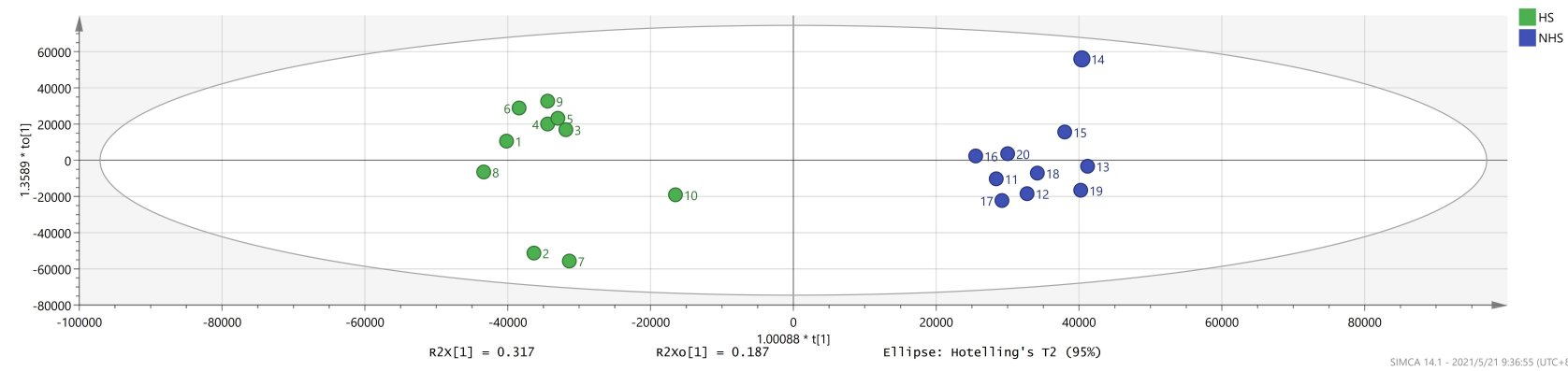

C

Fig. 5 PCA score plots of four groups and OPLS-DA plots of of primiparous cows and multiparous cows

A: PCA score plots of different groups and each dot stands for a serum sample of four groups; B: OPLS-DA plots of primiparous cows; C: OPLS-DA plots of multiparous cows.

GC-MS identified the different metabolites between heat stress (average THI in calving month $=70.30$ ) and non

heat stress (average THI in calving month $=59.45$ ) groups of primiparous and multiparous cows. According to the metabolic candidates, a heat map was constructed as shown in Fig. 6. A total of 15 and 11 metabolic candidates were obtained in primiparous and multiparous cows, respectively. The concentrations of L-threonine and D-fructose in the HS group of primiparous cows were higher than in the NHS group of primiparous cows $(P<0.01)$. Urea and dodecane in the HS group were higher than in the NHS group of multiparous cows $(P<0.01)$. Four different metabolites were found in both primiparous cows and multiparous cows: L-alanine, glycine, serine, and DL-ornithine, and the levels were lower in the HS group compared to the NHS group of primiparous cows. However, the opposite result was found in multiparous cows, in which the abundance was higher in the HS group. 

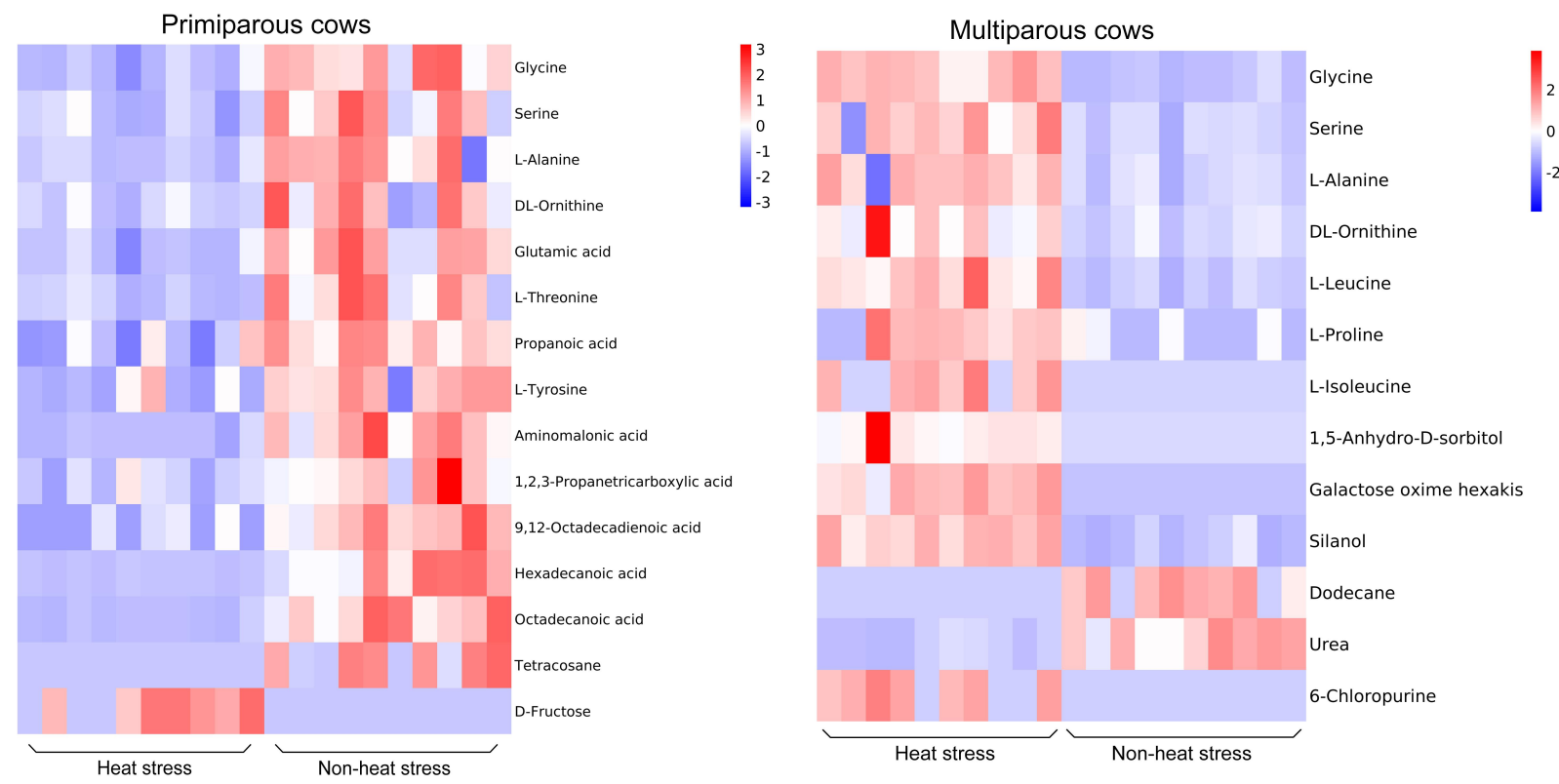

Fig. 6 Heat map representation of metabolite concentration of the HS and NHS samples.

The pathway enrichment analysis and pathway topology analysis of metabolic candidates were performed by

metaboanalyst 4.0 (http://www.metaboanalyst.ca). The Kyoto Encyclopedia of Genes and Genomes (KEGG,

http://www.genome.jp/kegg/) was used to reveal metabolic pathways. A total of 30 and 15 pathways were related to

primiparous and multiparous cows, respectively (Fig. 7), and the pathways with $\mathrm{P}$ values $<0.05$ and impact value $>0$

are listed in Table 2. The metabolic candidates in the primiparous cows were mainly involved in 8 pathways that are

related to translation, carbohydrate metabolism, amino acid metabolism, metabolism of other amino acids, metabolism

of cofactors and vitamins, and lipid metabolism. The metabolic candidates in the multiparous dairy cows were mainly

involved in the pathways of aminoacyl-tRNA biosynthesis; valine, leucine, and isoleucine biosynthesis; glycine, serine,

and threonine metabolism; valine, leucine, and isoleucine degradation; and glyoxylate and dicarboxylate metabolism,

which are related to translation, amino acid metabolism, and carbohydrate metabolism. The common metabolic 
226 Table 2. Affected metabolic pathways based on KEGG classification

\begin{tabular}{lll}
\hline Class $\quad$ Pathway Name & Metabolites & P-value \\
\hline
\end{tabular}

Primiparous cows

Glycine, Serine, L-Alanine,

Translation

Aminoacyl-tRNA

L-Threonine, L-Tyrosine, $\quad<0.01$

0.24

biosynthesis

Glutamic acid

Glyoxylate and

Carbohydrate

dicarboxylate

metabolism

metabolism

Glycine, serine and

Serine, Glycine, L-Threonine $\quad<0.01 \quad 0.38$

threonine metabolism

Alanine, aspartate and

Amino acid

glutamate metabolism

metabolism

Phenylalanine, tyrosine

and tryptophan

L-Tyrosine

$<0.05$

0.25

biosynthesis

Metabolism of

Glutathione metabolism

Glycine, Glutamic acid

$<0.05$

0.05

other amino acids

Metabolism of

Porphyrin and

cofactors and

chlorophyll metabolism
Glycine, Glutamic acid $\quad<0.05 \quad 0.08$

vitamins 
Linoleic acid

Lipid metabolism
Multiparous cows

9,12-Octadecadienoic acid $\quad=0.05 \quad 0.75$

metabolism

Glycine, Serine, L-Alanine,

Aminoacyl-tRNA

Translation

L-Isoleucine, L-Leucine, $\quad<0.01$

0.24

biosynthesis

L-Proline

Valine, leucine and

L-Leucine, L-Isoleucine $\quad<0.01 \quad 0.25$

isoleucine biosynthesis

Amino acid

Glycine, serine and

Glycine, Serine

$<0.05 \quad 0.36$

metabolism threonine metabolism

Valine, leucine and

L-Isoleucine, L-Leucine $\quad<0.05 \quad 0.04$

isoleucine degradation

Glyoxylate and

Carbohydrate

dicarboxylate

Serine, Glycine

$<0.05$

0.15

metabolism

metabolism

Pathway of common metabolic candidates

Aminoacyl-tRNA

Translation

Glycine, L-Serine, L-Alanine $\quad<0.01$

0.14

biosynthesis

Glyoxylate and

Carbohydrate

dicarboxylate

L-Serine, Glycine

$<0.01$

0.15

metabolism

metabolism 
Amino acid Glycine, serine and

L-Serine, Glycine $\quad<0.01 \quad 0.36$

metabolism threonine metabolism
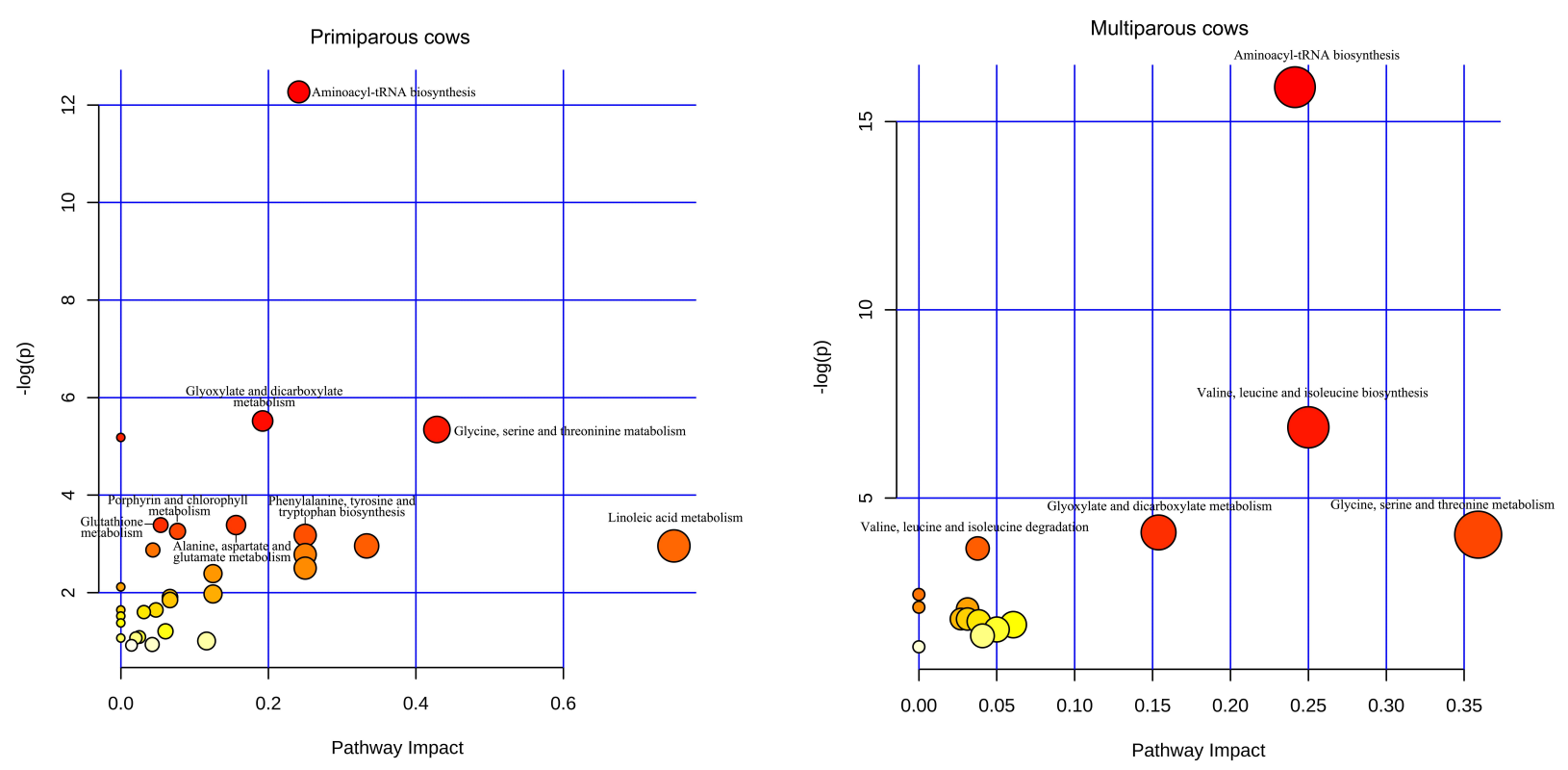

Fig. 7 Pathway topology analysis related to primiparous cows and multiparous cows.

\section{Discussions}

Studies have demonstrated a negative effect of heat stress on daily milk yield of dairy cows. Bouraoui et al. (2002)

THI value increased from 68 to 78. Collier et al. (2012) found milk yield decreased $2.2 \mathrm{~kg} / \mathrm{day}$ when daily THI was 68 .

Dunn et al. (2014) studied the effect of heat stress on milk yield in the UK, and milk yield decreased during the heatwaves of 2003 and 2006. A study by Zimbelman et al. (2009) indicated that milk yield decreases by an average of

$2.2 \mathrm{~kg}$ when animals experience a minimum THI of 65 or greater. The results of previous studies above were similar with the results of current study. In the present study, when compared with the cows that calved in June, the average daily milk yield of primiparous cows that calved in September and October increased by $19.15 \%$ and $13.83 \%$, respectively. However, the average daily milk yield of multiparous cows increased by $2.86 \%$ and $7.64 \%$, respectively. 
239

240

241

242

243

244

245

246

247

These results indicate that the effect of THI on milk yield may be cumulative and delayed, and the multiparous cows are more susceptible to higher THI, which supported the hypothesis that the damage degree of calculated THI on dairy cows was more severe after calving than that before calving, and the effect of THI on multiparous cows was more severe than multiparous cows. In agreement with the present study by Bernabucci et al. (2014), milk yield started to decline when THI ranged from 73 to 76 , and multiparous cows were more susceptible to heat stress than primiparous cows. The negative effects of heat stress on milk yield can be explained by decreased dry matter intake and decreased rumination and nutrient absorption (Liu et al. 2008; Baumgard and Rhoads 2012). Furthermore, there is an increase in peripheral blood flow for cooling, and mammary blood flow is reduced, which contributes to lower milk yield (West, 2003).

MDA is a product of lipid peroxidation, and previous studies have used increased levels of MDA to represent the imbalance between oxidants and antioxidants (Sharma, et al. 2011). Also, SOD, GSH-PX, and T-AOC are biomarkers for antioxidant status. The present study found that MDA was usually higher in cows that calved in June and July during the experimental period, especially in primiparous dairy cows compared to those that calved in September and October, which indicated that the cows calved in June and July were affected by heat stress. The concomitant increase in MDA, SOD, GSH-PX, and T-AOC may be a reaction of oxidative -antioxidative balance and a compensatory mechanism of homeostatic control in order to decrease the risk of oxidative damage (De et al. 1992). Consequently, heat stress affected the oxidative status, and the antioxidant mechanism would be activated by increasing the levels of SOD, GSH-PX, and T-AOC. Bernabucci et al. 2002 found that SOD was higher in cows that gave birth during the summer when THI ranged from about 71.2 to 75.2 , which is similar with the results of the current research. Safa et al. (2019) found that the MDA and T-AOC were higher in heat-stressed cows, heat-stressed cows exhibited higher rectal temperatures, and milk yield decreased by $1442 \mathrm{~kg}$ over the whole lactation period when compared with cooled cows, 
260

261

262

263

264

265

266

267

268

269

270

271

which is similar to the findings on milk yield and serum index in the current study.

Potential metabolic pathways that heat stress affected included aminoacyl-tRNA biosynthesis, amino acid metabolism, and carbohydrate metabolism of multiparous cows, and in addition to these, metabolism of cofactors and vitamins and lipid metabolism were influenced in primiparous cows. Amino acids are important substrates for the synthesis of proteins, and most of them in the present study are involved in the pathway of aminoacyl-tRNA biosynthesis. Aminoacyl-tRNAs are essential substrates for translation, providing precursors for the synthesis of proteins (Sheppard et al. 2008). Glycine is synthesized from serine, threonine, choline, glyoxylate, and hydroxyproline. Serine is derived from the diet or synthesized from glucose and glutamic acid, and alanine provides the amino group for glyoxylate (Wang et al. 2013; Thompson and Richardson 2014). Also, serine, glycine, and glutamic acid are involved in glyoxylate and dicarboxylate metabolism. Furthermore, glycine plays a critical role in anti-oxidative reactions by stimulating the synthesis of glutathione and reducing oxidative stress (Wang et al. 2014), and Senthilkumar et al. (2004) found that glycine inhibits the oxidative stress by increasing the GSH-Px and SOD in livers and brains of rats. The levels of amino acids in the HS group of primiparous cows were lower except for threonine, when compared with the NHS group. This could be due to the effect of heat stress, as animals will consume amino acids to synthesize antioxidant enzymes to resist heat stress and maintain an oxidative-antioxidative balance. However, the opposite results were found in multiparous cows, this could be due to the multiparous cows were more sensitive to heat stress than primiparous cows and the synthesis of antioxidant enzymes was restrained, which could explain that SOD, T-AOC and GSH-Px was higher in primiparous cows than that in multiparous cows. 9,12-Octadecadienoic acid is one isomer of conjugated linoleic acid (CLA) have antioxidant properties (Yurawecz et al. 1995). And the present study showed 9,12-Octadecadienoic acid in the serum of NHS group was higher when compared with HS group in primiparous cows. 


\section{Conclusions}

This study demonstrated that heat stress negatively affected the milk yield and thus caused the elevation of the serum oxidative and antioxidative index. Metabolic biomarkers associated with the heat stress in serum were found which providing the basis of evaluating indicator between heat stress and non heat stress groups in primiparous and multiparous cows. Moreover, we found that the cows were more susceptible to the heat stress after calving than that before calving, and the multiparous cows were more sensitive to heat stress than the primiparous cows, and discover the candidate biomarkers in serum.

\section{Funding}

The study was supported by the National Natural Science Foundation of China (31902185) and the Preferential Funding of Science and Technology Innovation and Entrepreneurship Projects for Returned Overseas Scientific Research Personnel in Jilin Province (G11).

This research received no external funding.

\section{Conflict of interest}

The Authors declare that they have no conflict of interest.

\section{Reference}

Armstrong, D.V. 1994. Heat Stress Interaction with Shade and Cooling. Journal of dairy science 77: 2044-2050.

Baumgard, L.H., and Rhoads, R.P. 2012. RUMINANT NUTRITION SYMPOSIUM: Ruminant Production and Metabolic Responses to Heat Stress. Journal of Animal Science 90: 1855-1865.

Bernabucci, U., Biffani, S., Buggiotti, L., Vitali, A., Lacetera, N., and Nardone, A. 2014. The effects of heat stress in Italian Holstein dairy cattle. Journal of dairy science 97: 471-486. 
302

303

304

305

306

307

Bernabucci, U., Ronchi, B., Lacetera, N., and Nardone, A. 2002. Markers of Oxidative Status in Plasma and Erythrocytes of Transition Dairy Cows During Hot Season. Journal of dairy science 85: 2173-2179.

Bouraoui, R., Lahmar, M., Majdoub, A., Djemali, M., and Belyea, R.L. 2002. The relationship of temperature-humidity index with milk production of dairy cows in a Mediterranean climate. Animal Research 51: 479-491.

Bouwstra, R.J., Goselink, R.M.A., Dobbelaar, P., Nielen, M., Newbold, J.R., and Van Werven, T. 2008. The relationship between oxidative damage and vitamin $\mathrm{E}$ concentration in blood, milk, and liver tissue from vitamin $\mathrm{E}$ supplemented and nonsupplemented periparturient heifers. Journal of dairy science 91: 977-987.

Castillo, C., Hernandez, J., Valverde, I., Pereira, V., Sotillo, J., Alonso, M.L., and Benedito, J.L. 2006. Plasma malonaldehyde (MDA) and total antioxidant status (TAS) during lactation in dairy cows. Research in veterinary Science 80: 133-139.

Chen, X., Liu, Y.Z., Demelash, N., Dong, J.N. Xiao, J., Zhao, W., Lang, M., Han, Z.Y., Zhang, X.F., Wang, T., Sun, Z., Zhen, Y.G., and Qin, G.X. 2019. Effects of different probiotics on the gut microbiome and metabolites in the serum and caecum of weaning piglets. South African Journal of Animal Science 49: 494-504.

Collier, R.J., Hall, L.W., Rungruang, S., and Zimbleman, R.B. 2012. Quantifying heat stress and its impact on metabolism and performance. Proceedings of the Florida Ruminant Nutrition Symposium 74-83.

Dahl, G.E., Tao, S., and Laporta, J. 2017. TRIENNIAL LACTATION SYMPOSIUM/BOLFA: Late gestation heat stress of dairy cattle programs dam and daughter milk production. Journal of animal science 95: 5701-5710.

De Quiroga, G.B., Lopeztorres, M., and Perezcampo, R. 1992. Relationship between antioxidants, lipid peroxidation and aging. EXS 62: 109-123.

Du Preez, J.H., Giesecke, W.H., and Hattingh, P.J. 1990a. Heat stress in dairy cattle and other livestock under southern African conditions. I. Temperature-humidity index mean values during the four main seasons. Onderstepoort Journal 
of Veterinary Research 57: 77-87.

Du Preez, J.H., Hattingh, P.J., Giesecke, W.H., and Eisenberg, B.E. 1990b. Heat stress in dairy cattle and other livestock under southern African conditions. III. Monthly temperature-humidity index mean values and their significance in the performance of dairy cattle. Onderstepoort Journal of Veterinary Research 57: 243-248.

Dunn, R.J., Mead, N.E., Willett, K.M., and Parker, D.E. 2014. Analysis of heat stress in UK dairy cattle and impact on milk yields. Environmental research letters 9: 064006.

Gantner, V., Bobic, T., Gantner, R., Gregic, M., Kuterovac, K., Novakovic, J., and Potocnik, K. 2017. Differences in response to heat stress due to production level and breed of dairy cows. International journal of biometeorology 61: $1675-1685$

Igono, M.O., and Johnson, H.D. 1990. Physiologic stress index of lactating dairy cows based on diurnal pattern of rectal temperature. Journal of Interdisciplinary Cycle Research. 21: 303-320.

Kadzere, C.T., Murphy, M.R., Silanikove, N., and Maltz, E. 2002. HEAT STRESS IN LACTATING DAIRY COWS: A REVIEW. Livestock production science. 77: 59-91.

Konvicna, J., Vargova, M., Paulikova, I., Kovac, G., and Kostecka, Z. 2015. Oxidative stress and antioxidant status in dairy cows during prepartal and postpartal periods. Acta Vet Brno. 84, 133-140.

Liu, Z.L., Chen, P., Li, J.M., Lin, S.B., Wang, D.M., Zhu, L.P., and Yang, D.P. 2008. Conjugated linoleic acids (CLA) moderate negative responses of heat-stressed cows. Livestock science 118: 255-261.

NRC (1971) A Guide to Environmental Research on Animals, Washington, DC: National Academy Science.

Ravagnolo, O., Misztal, I., and Hoogenboom, G. 2000. Genetic Component of Heat Stress in Dairy Cattle, Development of Heat Index Function. Journal of Dairy Science 83: 2120-2025.

Safa, S., Kargar, S., Moghaddam, G.A., Ciliberti, M.G., and Caroprese, M. 2019. Heat stress abatement during the 
344 postpartum period: effects on whole lactation milk yield, indicators of metabolic status, inflammatory cytokines, and biomarkers of the oxidative stress. Journal of animal science 97: 122-132.

Savaliya, B.D., Parikh, S.S., Makwana, R.B., Patbandha, T.K., Gamit, P.M., and Murthy, K.S. 2019. Effect of Microclimate Alteration on Temperature Humidity Index (THI), Milk Production and Milk Composition in Jaffrabadi Buffaloes during Summer. International Journal of Current Microbiology and Applied Sciences 8: 1379-1385.

Senthilkumar, R., Viswanathan, P., and Nalini, N. 2004. Effect of glycine on oxidative stress in rats with alcohol induced liver injury. Die Pharmazie. 59: 55-60.

Sharma, N., Singh, N.K., Singh, O.P., Pandey, V., and Verma, P.K. 2011. Oxidative Stress and Antioxidant Status during Transition Period in Dairy Cows. Asian-australasian Journal of Animal Sciences 24: 479-484.

Sheppard, K., Yuan, J., Hohn, M.J., Jester, B. Devine, K.M., and Soll, D. 2008. From one amino acid to another: tRNA-dependent amino acid biosynthesis. Nucleic Acids Research 36: 1813-1825.

Tian, H., Nan, Z., Wang, W., Cheng, J., Li, S., Zhang, Y., and Wang, J. 2016. Integrated Metabolomics Study of the Milk of Heat-stressed Lactating Dairy Cows. Scientific Reports 6: 24208.

Thompson, J.S., and Richardson, K.E. 1967. Isolation and Characterization of an 1-Alanine:Glyoxylate Aminotransferase from Human Liver. Journal of Biological Chemistry 242: 3614-3619.

Wang, W., Wu, Z., Dai, Z., Yang, Y., Wang, J., and Wu, G. 2013. Glycine metabolism in animals and humans: implications for nutrition and health. Amino Acids 45: 463-477.

Wang, W., Wu, Z., Lin, G., Hu, S., Wang, B., Dai, Z., and Wu, G. 2014. Glycine Stimulates Protein Synthesis and Inhibits Oxidative Stress in Pig Small Intestinal Epithelial Cells. Journal of Nutrition 144: 1540-1548.

West, J. W. 2003. Effects of Heat Stress on Production in Dairy Cattle. Journal of dairy science 86: 2131-2144. 
365 products of conjugated octadecadienoic acid. Lipids. 30: 595-598.

366 Zhao, Y.N., Zhao, J.Y., Zhao, C.X., Zhou, H.N., Li, Y.L., Zhang, J.J., Li, L.L., Hu, C.X., Li, W.Z., Peng, X.J., Lu, X.,

367 Lin, F.C., and Xu, G.W. 2015. A metabolomics study delineating geographical location-associated primary metabolic

368 changes in the leaves of growing tobacco plants by GC-MS and CE-MS. Scientific Reports 5: 16346.

369 Zhao, W. Chen, X. Xiao, J. Chen, X.H. Zhang, X.F. Wang, T. Zhen, Y.G. and Qin, G.X., 2019. Prepartum body

370 condition score affects milk yield, lipid metabolism, and oxidation status of Holstein cows. Asian-australasian

$371 \quad$ Journal of Animal Sciences 32: 1889-1896.

372 Zimbelman, R.B. Rhoads, R.P. Rhoads, M.L. Duff, G.C. Baumgard, L.H. and Collier, R.J. 2009. A re-evaluation of the

373 impact of temperature humidity index (THI) and black globe humidity index (BGHI) on milk production in high

374 producing dairy cows. Proceedings of the Southwest Nutrition Conference (ed. RJ Collier) 158-169. 